\title{
Cloning and Designing Vector Carrying GmEXPl Gene Isolated from Local Soybean Cultivar Sonla, Vietnam
}

\author{
Lo Thanh Son, Le Van Son, Nguyen Vu Thanh Thanh, and Chu Hoang Mau
}

\begin{abstract}
Soybeans (Glycine max (L.) Merrill) are short-duration industrial crops which have high economic and nutritional values, and play an important role in improving soil fertility and sustainable use of cultivated land resources. Soybeans have low level of drought tolerance, thus it is of great necessity to study on approaches to improve their drought tolerance, including using genes related to the root elongation. The GmEXP1 gene which expresses expansin, a key protein in cell expansion, is one of those genes. In this study, we amplified, cloned and determined the GmEXPI gene sequence from local soybean SL1 cultivar with best vigorous root systems. GmEXP1 gene is 790 bp in length, encoding 255 amino acids. Transgenic vector carrying $G m E X P 1$ gene has been designed successfully (pCB301-GmEXP1) and transformed into tobacco plants $(N$. tabacum K326). These results form the basis for generation of transgenic soybean cultivars overexpressing GmEXP1, aiming to improve the drought tolerance based on the root elongation of soybean cultivars in Vietnam.
\end{abstract}

Index Terms-Expansin, GmEXP1 gene, gene transfer, local soybean, root elongation.

\section{INTRODUCTION}

Soybeans (Glycine max (L.) Merrill) are short-duration industrial crops which have high economic and nutritional value, as well as play an important role in improving soil fertility and sustainable use of cultivated land resources.. In recent years, the global warming and climate change affected the growth of soybean cultivars in Vietnam. Soybean belongs to the crops group which has low drought tolerance, thus the application of biotechnology to improve the drought tolerance of soybean has become interesting topics of Vietnamese scientists.

Two major mechanisms related to drought tolerance of plants is the osmotic pressure adjustment and the development of a strong root systems. Root system plays an important role in providing water to get to the life and activities of plant development.

The drought tolerant mechanism of plants closely related to the development of the root systems. Deeper rooting should improve soybean's ability to avoid water stress by increasing water uptake from deep soil layers [1]. During

Manuscript received December 6, 2013; revised March 19, 2014

Lo Thanh Son is with the Department of Biology, Taybac University, Vietnam.

Le Van Son is with the Department of Plant Cell Biotechnology, Institute of Biotechnology, VAST, Vietnam.

Nguyen Vu Thanh Thanh is with the Department of Genetics, Faculty of Life Science, Thainguyen University, Vietnam.

Chu Hoang Mau is with the Department of Genetics and modern Biology, faculty of Biology, Thainguyen University, Vietnam (e-mail: mauchuhoang@gmail.com). growing process, plant cells secrete a protein called expansin, which unlocks the network of wall polysaccharides. Expansin's action has puzzling implications for plant cell-wall structure. The recent explosion of gene sequences and expression data has given new hints of additional biological functions for expansins [2]. Expansins are cell wall proteins, containing two known families, named alphaand beta-expansins, and they comprise large multigene families whose members show diverse organ-, tissue- and cell-specific expression patterns [3]. Expansins belong to a group of extracellular proteins that directly modify the mechanical properties of plant cell walls, leading to turgor-driven cell extension. Based on phylogenetic analysis, the studies have shown that the three plant expansin subfamilies ( $\alpha, \beta$ và $\gamma$-expansin) arose and began diversifying very early in, colonization of land by plants [4].

Expansins are plant proteins that can induce extension of isolated cell walls and are proposed to mediate cell expansion and is considered a major protein affects the expansion of the plant cell [5]. Lee et al. (2003) isolated expansin genes (EXP1) from mRNA of soybean and found that the expression levels of GmEXP1 were very high in the roots of 1- to 5-d-old seedlings, in which rapid root elongation takes place [6]. Furthermore, GmEXPl mRNA was most abundant in the root tip region, where cell elongation occurs, but scarce in the region of maturation. The GmEXP1 gene plays an important role in root development in soybean, especially in the elongation and initiation of the primary and secondary roots [6]. Among the local soybean cultivars in Vietnam, cultivar SL1 was judged to be the most vigorous root systems. Thus we used cultivar SL1 for the isolation of GmEXP1 gene with the aim of creating materials for gene transfer to improve drought tolerance of soybean crops.

In this study, we present some results on amplification of GmEXP1 gene from mRNA isolated from soybean cultivar SL1 in Vietnam, designing a plant expression vector carrying GmEXP1 structure and transferred it into tobacco cultivars (Nicotiana tabacum).

\section{MATERIALS AND METHODS}

Local soybean cultivar Sonla (SL1) in Vietnam was supplied by Vietnam Academy of Agricultural Sciences (2013). Tobaco cultivars $N$. tabacum K326 was supplied by Department of Plant Cell Technology, Institute of Biotechnology, Vietnam.

Total RNA was isolated using Trizol Reagent KIT, cDNA was synthesized using the Maxima ( ${ }^{\circ}$ First Strand cDNA Synthesis KIT. The cDNA was used as template for PCR to 
amplified encoding region of GmEXPl gene. From the information about sequence of GmEXPl gene in soybean on GenBank, code number AF516879, we designed primer pair SoyExpF/SoyExpR for the isolation of gene encoding region of GmEXPl gene:

\section{SoyExpF: CATGCCATGGATGGGCAAAATCATGCTTGT SoyExpR:ATTTGCGGCCGCTTAGAACTGAACTGGGCTAGA}

PCR products were examined by electrophoresis on a $0.8 \%$ agarose gel and purified by $\mathrm{JET}^{\mathrm{TM}}$ Gene Gel Extraction KIT; recombinant vector transformed into $E$. coli DH5 $\alpha$ cells with variable heat shock. Bacteria carrying recombinant vector were selected on antibiotic selective environment (carbenicilin, kanamycin). The strain carrying the recombinant vector were selected by colony-PCR with specific primers, were cultured in liquid LB supplemented environment antibiotic selection appropriate to collect biomass. Recombinant plasmids were obtained by extracting the molecular cloning methods [7].

To transfer GmEXPl structure into plants and be able to check protein expression, we designed pCB301 recombinant vector carrying the target gene structure consists of the following

components:
CaMV35S_GmEXP1_c-myc_KDEL_polyA. Recombinant vector transferred into Agrobacterium tumefaciens cells by electrical pulses $(2.5 \mathrm{kV}, 25 \mu \mathrm{F}, 200 \Omega)$. The bacteria carrying the recombinant gene structure is multiplied with large biomass and used to infect into tobacco plants.

\section{RESULTS AND DISCUSSION}

\section{A. Cloning and Sequence Determining of GmEXP1 Gene from Soybean Cultivar SL1}

From cultivar SL1, we extracted total RNA from the grown domain of roots and synthesized cDNA with random primers (random hexamer primers). Coding region of GmEXPl gene was amplified by PCR with specific primer pair (SoyExpF/SoyExpR) and RT-PCR products obtained a very special brand with length approximately $0.79 \mathrm{~kb}$ as expected. (Fig. 1 a). PCR products were purified and inserted into cloning vector pBT_2705bp and transformed into $E$. coli $\mathrm{DH} 5 \alpha$. We selected clones carrying recombinant plasmid, extracted recombinant plasmids and checked the size of the insert by BamHI. The results confirmed that plasmid carrying an insert with expected size (Fig. 1 b).
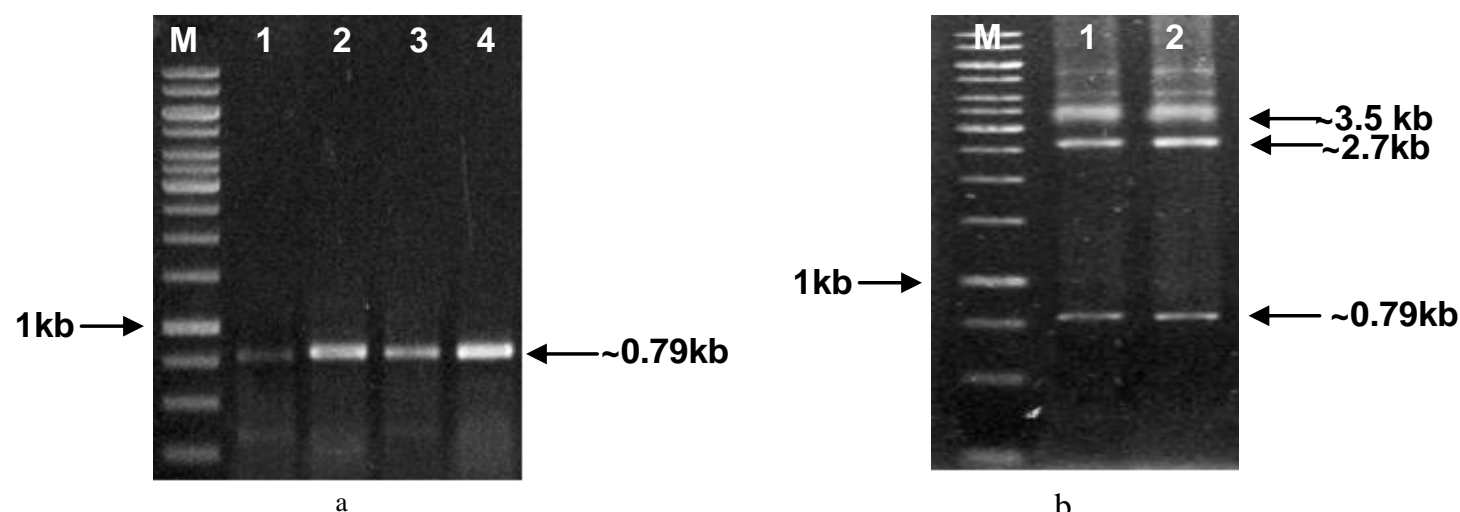

b

Fig. 1. a) PCR products of the GmEXP1 gene (cDNA) amplifed from soybean cultivar SL1 and b) Products from plasmid digestion by BamHI (M: DNA Marker $1 \mathrm{~kb})$.

The results of gene sequencing showed that GmEXP1 gene is $790 \mathrm{bp}$ in length, encoding 255 amino acids. Results comparing with gene sequences GmEXPI published on GenBank by using BLAST in NCBI show that GmEXPl gene sequence isolated from soybean cultivar SL1 is similar to that in GmEXP1 gene sequence (code number: AF516879) on Genbank with 99\% of similar coefficients (only different on 5 nucleotides and 1 amino acid). This result confirmed that we have successfully cloned GmEXPl gene from the soybean cultivar SL1 and GmEXPl gene sequence has been registered on GenBank with code is HG792075.

\section{B. Construction of Transgenic Vector Carrying GmEXPl Gene}

Vector pBT carrying GmEXPl gene was digested by two restriction enzymes $N c o I$ and NotI to cut out GmEXP1 gene (DNA fragments with the size of $0.79 \mathrm{~kb}$ ). Gen GmEXPl was then inserted into vector pRTRA to create the recombinant structure carrying the transgene
(pRTRA-GmEXPl). Recombinant vector pRTRA-GmEXPl was transformed into $E$. coli $\mathrm{DH} 5 \alpha$ cells. The transformed $E$. coli cells were selected and cultured in LB environment supplement with carbenicilin. Extracted plasmids were then tested for the presence of GmEXP1 gene by PCR with specific primer pair SoyExpF/SoyExpR (Fig. 2 a).

Recombinant vector pRTRA_GmEXPl was cut by HindIII to obtain two DNA fragments with the approximate size of $1.6 \mathrm{~kb}$ and $2.3 \mathrm{~kb}$, in which the $1.6 \mathrm{~kb}$ DNA fragment contains our target gene (CaMV35S_GmEXP1_c-myc_KDEL_polyA). Structure CaMV35S_GmEXP1_c-myc_KDEL_polyA was inserted in vector $\mathrm{pCB} 301$ to create transgenic vector carrying the transgene

(pCB301_CaMV35S_GmEXP1_c-myc_KDEL_polyA). This vector was cloned into $E$. coli $\mathrm{DH} 5 \alpha$. We then used colony-PCR with specific primer pair SoyExpF/SoyExpR to select colonies having GmEXPl gene (Fig. 2 b). Plasmid pCB301_CaMV35S_GmEXP1_c-myc_KDEL_polyA is 
extracted from positive colonies and transformed into

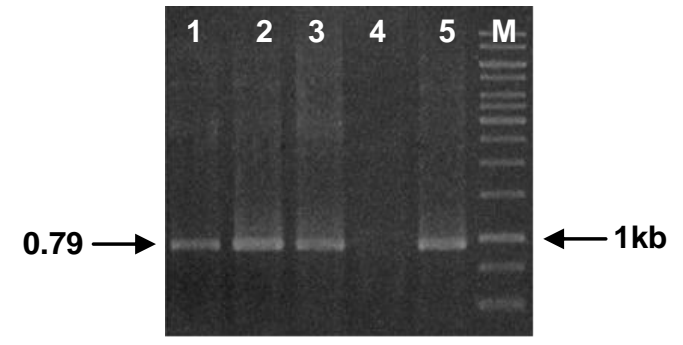

Fig. 2. a) PCR products of the GmEXP1 gene amplified from pETRA-GmEXP1 on gel agarose $0.8 \%$; b) Colony-PCR products of the $G m E X P 1$ gene from colony lines (+: positive control; -: negative control; 1, 2, 3, 4, 5, 6: colony lines).

\begin{tabular}{ccccc}
\multicolumn{2}{c}{ TABLE I: TRANSFORMATION AND REGERATION OF TOBACCO PLANTS CARRYING PCB301_CAMV35S_GMEXP1_C-MYC_KDEL_POLYA STRUCTURE } \\
\hline \hline No. & $\begin{array}{c}\text { Number of gene transfer } \\
\text { samples }\end{array}$ & $\begin{array}{c}\text { Number of samples } \\
\text { create buds }\end{array}$ & $\begin{array}{c}\text { Number of buds on medium for } \\
\text { generated roots }\end{array}$ & $\begin{array}{c}\text { Number of trees planted in } \\
\text { pots }\end{array}$ \\
\hline 1 & 30 & 30 & 88 & 74 \\
2 & 30 & 29 & 102 & 97 \\
3 & 40 & 38 & 277 \\
Sum & 100 & 97 & 242 \\
\hline \hline
\end{tabular}

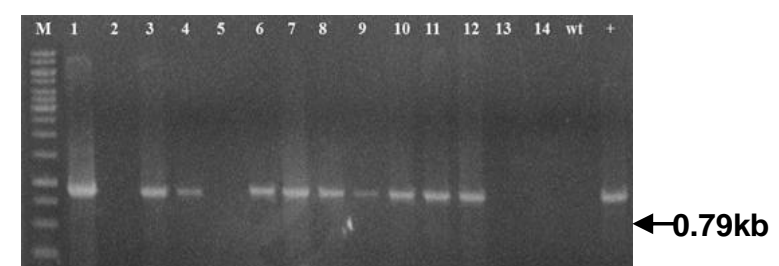

Fig. 3. PCR detection for the presence of transgene in transgenic tobacco plants (M: DNA marker 1kb; +: positive control; wt: non-transgenic tobacco plants; 1-14: transgenic tobacco lines).

\section{The Results Transformants Structure PCB301-GmEXPlinto Tobaco Cultivars (N.tabacum K326)}

Leaves of tobacco plants ( $N$. tabacum K326) were cut into $1 \times 1 \mathrm{~cm}$ pieces, soaked in cell suspension of recombinant A.tumefaciens in 10 minutes, and then regenerated on MS medium with added BAP. The well grown buds $(2-3 \mathrm{~cm})$ were excised and transferred into RM medium for root generation. The plantlets were grown in greenhouses. The results throughout the transformation and regeneration process are presented in Table I.

We have obtained 242 tobacco lines in total from 100 transformed samples. Analyses of 44 tobacco cultivars by PCR to check for presence of GmEXPl gene in the transgenic plants and the results showed that 32/44 regenerated plants tested positive for the PCR reaction (see Fig. 3).

Expansins have an important role in the phase of cell growth of root systems of soybean cultivars. Most of the experiments showed that at tissue containing growing cells, expansins altering the physical properties of the cell wall by loosening hydrogen bonding, loosening bonding non-chemotherapy between micro fiber of cellulose and loosening of polymer network [8]. Micro fibers of cellulose are connected together by the polysaccharide. The polysaccharide linked to surface of micro-fibers of cellulose and bonded together. Expansin protein can break the polysaccharide bonds of micro-fiber surface or break the bonds between the polysaccharide and the distance between the micro fibers of cell walls easily be pushed stretch both horizontally and vertically. Expansin can move easily between the micro-fibers of cellulose of cell walls and in contact with the polymer adhesive points. This facilitates the growth phase of cells to be easily done [2]. Expansin have more in the epidermal cells and in the cell layer at growth domain of roots and the lateral roots, but very rare in the mature domain [6]. Soybeans is group of plants have drought tolerance with low level, so approach studying the of elements impact on the root elongation in soybean plants forms the basis of the application of gene transfer technique to improve drought tolerance of soybean plants. Along with the successful transformants of the GmEXPl gene isolated from soybean cultivars into tobacco plants, it can be said this is the basis to be able to create transgenic soybean cultivars carrying structure pCB301-GmEXP1.

\section{CONCLUSION}

GmEXPl gene has been isolated and cloned from local soybean cultivar SL1 (Sonla, Vietnam). GmEXP1 gene has the size of $790 \mathrm{bp}$, encoding 255 amino acids. Transgenic vector carrying GmEXPl gene has been designed successfully and transformed into tobacco plants (N. tabacum K326). This work forms the basis for the generation of transgenic soybean cultivars carrying structure pCB301-GmEXP1, aiming to improve the drought tolerance soybean cultivars in Vietnam by using approaches to develop their root system.

\section{ACKNOWLEDGMENT}

This work has been done by the financial support of the Project DH2012-TN01-04. The authors would like to express their gratefulness for the help of Key Laboratory of Gene 
Technology, Institute of Biotechnology, Vietnam.

\section{REFERENCES}

[1] T. C. Kaspar, H. M. Taylor, and R. M. Shibles, "Taproot elongation rates of Soybean cultivars in the glasshouse and their relation to field rooting depth," Crop Sci, vol. 24, pp. 916-920, 1984.

[2] D. J. Cosgrove, "Loosening of plant cell walls by expansions," Nature, vol. 407, pp. 321-326, 2000.

[3] D. J. Cosgrove, L. C. Li, and H. T. Cho, "Hoffmann-Benning S, Moore $\mathrm{RC}$, Blecker D (2002) The growing world of expansions," Plant Cell Physiol., vol. 43, no. 12, pp. 1436-44.

[4] Y. Li et al., "Plant expansins are a complex multigene family with an ancient evolutionary origine," Plant Physiol, vol. 128, pp. 854-864. 2002.

[5] F. Chen, "Peetambar Dahal, and Kent J. Bradford (2001) Two Tomato Expansin Genes Show Divergent Expression and Localization in Embryos during Seed Development and Germination," Plant Physiol, vol. 127, no. 3, pp. 928-936.

[6] D. K. Lee, J. H. Ahn, S. K. Song, Y. D. Choi, and J. S. Lee, "Expression of an Expansin gene is correlated with root elongation in soybean," Plant Physiol, vol. 131, 985-977, 2003.

[7] J. Sambrook and D. W. Russell, A. Molecular Cloning Laboratory Manual, 3rd ed. Cold Spring Harbor Laboratory, Cold Spring Harbor, NY, 2001.

[8] D. A. Brummall, M. H. Harpester, P. M. Civello, J. M. Palys, A. B. Bennett, and P. Dunsmuir, "Modification of Expansin Protein
Abundance in Tomato Fruit Alters Softening and Cell Wall Polymer Metabolism during Ripening," Plant Cell, vol. 11, pp. 2203-2216, 1999.

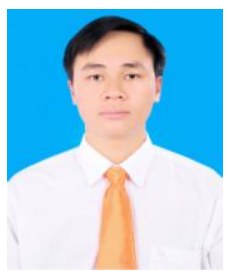

Lo Thanh Son was born in Vietnam. He obtained master's degree in genetics at the Hanoi National University of Education (2007). He is a lecturer in Faculty of Bio-chemistry, Taybac University. His research interest includes molecular biology of plants, application of transgenic techniques aiming to improve the drought tolerance of soybean cultivars in Vietnam.

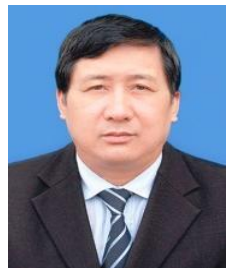

Chu Hoang Mau was born in Vietnam. He obtained his $\mathrm{PhD}$ degree in genetics at Institute of Biotechnology, VAST, Vietnam (2001). He is a professor in the Department of Genetics and modern Biology, faculty of Biology, Thainguyen university. His research interest includes molecular biology of plants, application of transgenic techniques aiming to improve the drought tolerance and improve resistance to virrus of soybean cultivars in Vietnam. Prof. Chu has some publications (Genes and drought tolerance of soybean, VNU Publishing House, Hanoi, 2011) 